\title{
CORRESPONDENCE
}

Health and safety at work

J D G Hammer, BA.

Shortcomings of the NHS: a yawning chasm

G F G Woodman, MrCGP...........

: a yawning

Lieutenant-Colonel M J G Thomas,

DTM\&H; W D Mackenzie, $M B$, and P J C

Chapman, DPH.

Heat stroke in a "run for fun"

R L Hughson, PHD, and J R Sutton, $\operatorname{FrCP}(C) 1158$

Natural history and prognosis of

recurrent breast cancer

R L Souhami, MD, and others........ 1158

Surma and lead poisoning

S S Bakhshi, MFCM.............

Beta-blockers in treatment of

hypertension

$\mathrm{K}$ Abt; M Danielsson, MD, and others;

R G Wilcox, MRCP. .

Cost-effectiveness studies

T W Davies, MD, and P Smith, BA . . . . . 1160

African travel

S G Barber, MRCP............. 1160

Razoxane in treatment of acute myeloid

leukaemia

K Hellmann, DM; Daisy Obeid, MRCPATH,

and $\mathrm{K}$ Paule Cotter, MD.

Hormone receptors in breast cancer

J Appelbaum, MD . . . . . . . . . . . 1161

Thyroid function tests

P Sheridan, MRCP, and R B Payne, FRCPATH 1162
Postpartum haemorrhage after induced and spontaneous labour

D D Mathews, FRCOG; M Thiery, MD ... 1162

Radiology work load

M J Brindle, FRCPC . . . . . . . . . . . 1162

Dopamine and dobutamine

L I Goldberg, MD; A K Yates, FrCs...... 1163

Alpha-fetoprotein levels in cirrhosis and cancer of the liver

J Vilaseca, MD, and others......... 1163

Behçet's disease

A C Newland, MRCP, and M J Wood, MRCP 1163

Eyesight standard for driving

A E Wilson, Mrcs............... 1164

Hypotensive effect of propranolol and

phenoperidine in tetanus

$\mathrm{K}$ L Woods, MRCP.

Body weight and endocrine function in anorexia nervosa

A Wakeling, MRCPSYCH, and others..... 1164

Phenothiazine-induced dystonic reaction while swimming

$M$ W Dysken, MD, and J M Davis, MD . . . 1164

Persistence of barbiturate prescribing

J A Sheikh, MB.

1165

olving clinical questions by research

N G L Harding, MB .............. 1165

Hypertension and oral contraceptives

M G Crane, MD, and others.......... 1165

Patient package inserts

A R G Calder, BSC.

Streptococcus bovis endocarditis with

carcinoma of the colon

S Ahmad, MD, and M K Meeran, MD ... 1166
Link between hepatoma and hepatitis $B$

G H Ree, MrCPED............... 116

Paraldehyde and plastic syringes

V'I Fenton-May, BPHARM, and Felicity

Lee, Msc.................... 1166

Interaction of warfarin with antacid constituents

J C McElnay, BSC, and others........ 1166

Absence of interaction of digoxin with

antacids under clinical conditions

J Cooke, MPHARM, and J A Smith, PHD . . . . 1166

Management of dermatomyositis

J R Jass, MB . .............. 1167

Pricing the consultants' contract

T McFarlane, MrCOG............ 1167

Use and abuse of medical women

Patricia E Price, MB............ 1167

Payment of ancillary staff

H P Watson, MrCGP ........... 1167

Prescribing and family planning

N A Chisholm, LRCP.

Facilities for private practice in NHS

hospitals

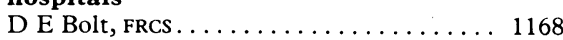

Points from letters Taking medical histories through interpreters ( $\mathrm{H} \mathrm{H} \mathrm{W} \mathrm{Bennett);} \mathrm{Use} \mathrm{of}$ orthotolidine (A R Lyne); Pain after hip replacement (B M Wroblewski); Pulmonary oedema associated with suppression of premature labour (M J A Maresh); Polio immunisation of parents (J W McCrone)............ 1168 Correction

Rectal carcinoma (Brown and Ritchie).. 1168
Correspondents are urged to write briefly so that readers may be offered as wide a selection of letters as possible. So many are being received that the omission of some is inevitable. Letters must be signed personally by all their authors.

As stated each week in "Instructions to authors" no letter will be acknowledged unless a stamped addressed envelope or an international reply coupon is enclosed.

\section{Health and safety at work}

SIR,-I welcome your balanced and positive leading article (9 September, $\mathrm{p} 715$ ) on health and safety at work; however, there are a few misunderstandings which I should like to clear up.

You lament the absence of guidance from the Health and Safety Executive on priorities for the allocation of resources to safety and health improvements. I can reassure your readers that, while the HSE pilot survey into health and safety in the medical services, which you mention, did not discuss priorities (which could not have been appropriate to a background discussion paper meant to encourage employers and unions to make up their own minds), we have made it clear in a subsequent paper that HSE inspectors are very willing to offer guidance on priorities in discussion with area management. This paper, "The Approach of the Health and Safety Executive to the Inspection of Hospitals and Health Services," has been sent to all area health authorities and hospital service unions and is available on request from the address at the end of this letter. It explicitly states, "As in the case of all other employers the inspectors will be prepared to discuss priorities with management, with a view to phasing less urgent matters."

Our inspection paper also deals with your fears of HSE "invasion" of the "territory of clinical practice." Your fears are apparently prompted by the section of the Health and Safety at Work Act which obliges all employers to ensure, so far as is reasonably practicable, that the health and safety of people not in their employ is not adversely affected by the work in progress. This section, as our paper says, is "primarily intended to cover the incidental effect of work activities on the health of the public." However, in the particular case of the health services the whole purpose of hospital work activity is to foster the health of the patient. So we say in our paper: "Inspectors will initially take the line that they will not concern themselves with the professional or nursing care of patients except as far as it may be necessary to do so when dealing with certain systems of work or the fitness of plant or equipment." That is the position until the legal situation of how, in equity, this section should apply to hospitals has been thoroughly discussed with all concerned.

In your leader you also refer to the possibility that the NHS might be exempt from enforcement. While it is true that many employees in the health services, and most in hospitals, are employed by the Crown, the Act does provide that the general obligations are binding on the Crown. In addition, the Health and Safety Commission has agreed to the executive's instituting a system of Crown notices which, though not ultimately enforceable at law, are available for use by inspectors in the sort of circumstances in which in industry they would issue a prohibition notice or improvement notice under the Act.

In order to co-ordinate the activities of inspectors, to draw together information about problems of health and safety in hospitals, and to provide a focus for discussion with management, professional staff, and employees I have nominated a senior inspector in the field to carry out this work-namely, Mr J Rudd, Area Director, South-west Area, HM Factory Inspectorate Health and Safety Executive, Inter City House, Mitchell Lane, Victoria Street, Bristol BS1 6AN.

It is my intention that inspection should be undertaken incisively and consistently but also with understanding of the problems and objectives of the Health Service. We are more than ready to discuss problems which arise and, where appropriate, to consider alternative approaches.

J D G HAMMER

Health and Safety Executive

M Chief Inspector of Factories

Regina House,

London NW1 5RR Road, 